\title{
Musca domestica Larva Lectin Induces Apoptosis in BEL-7402 Cells through a Mitochondria-Mediated Reactive Oxygen Species Way
}

\author{
Qi Zhao, Xiaohong CaO,* Bin Zeng, Chunling Wang, Le Yan, and Chengjian Xu \\ Key Laboratory of Food Safety and Sanitation, Ministry of Education, College of Food Engineering and Biotechnology, \\ Tianjin University of Science and Technology; No. 29, 13th Avenue, Tianjin Economy Technological Development Area, \\ Tianjin 300457, China. Received February 15, 2010; accepted May 14, 2010; published online May 24, 2010
}

\begin{abstract}
A lectin from Musca domestica larva was purified by affinity chromatography on a glactose-Sepharose 4B column. Musca domestica larva lectin (MLL) inhibited the growth of BEL-7402 cells in a time and concentrationdependent way. The results of Hoechst 33258 staining indicated that MLL induce BEL-7402 cells apoptosis based on the typical apoptotic morphological changes. Subsequently, we found that MLL treatment abrogated glutathione antioxidant system and induced mitochondria to generate reactive oxygen species (ROS) accumulation, resulting in reduction of mitochondrial transmembrane potential. The induction of cell apoptosis was caused by the upregulation of Bax, the downregulation of Bcl-2, the cytochrome $c$ release and the activation of the caspases pathways.
\end{abstract}

Key words lectin; Musca domestica larva; antitumor; apoptosis; mitochondrial path

Cancer was the disease with proliferation disorder and apoptosis obstacle. Apoptosis, ${ }^{1)}$ a type of programmed cell death, is an active process playing an essential role in embryonic development, homeostasis, remodeling, surveillance, and host defense mechanisms. Redundant and potentially deleterious cells were eliminated in the apoptosis process, and apoptosis was arguably the most potent defense against cancer. ${ }^{2,3)}$ Apoptosis is regulated by a network of signaling pathways and transcription factors, which is possible targeting for a rational tumor therapy. ${ }^{4)}$ In several apoptotic pathways, mitochondria played a critical role in apoptotic death induced by various stresses agents. ${ }^{5,6)}$ Cellular stresses trigger caspase activation by promoting release of mitochondrial components, ${ }^{7)}$ including cytochrome $c$, into the cytoplasm from the mitochondrial intermembrane space. Reactive oxygen species (ROS) generation is a cell death initiation signal that contributes to mitochondrial dysfunction and the subsequent drop in cellular ATP levels.

Musca domestica is a common insect of the family Muscidae. About $90 \%$ of all flies occurring in human habitations are houseflies. Musca domestic can transport disease-causing organisms, but they could keep their normal physical conditions even living in the environment full of pathogenic microorganism. According to "Compendium of Materia Medica," Musca domestica larvae powder is an important component of Chinese herbal medicine, people use it to cure ecthyma, osteomyelitis, decubital necrosis and malnutritional stagnation. Some Indian indigenous people cure trauma with fresh larvaes because the larveas eat necrotic tissue as their food. There are several activated substances in Musca domestica, such as prophenoloxidase, antibacterial protein/peptide, lysozyme and lectin. ${ }^{8)}$

Lectins, a class of carbohydrate-binding proteins, were known to be able to agglutinate cells. ${ }^{9)}$ They were ubiquitous in nature, such as in microorganisms, ${ }^{10}$ ) animals ${ }^{11)}$ and plants. ${ }^{12)}$ And they played important roles in cellular events like proliferation, ${ }^{13)}$ antibacterial, ${ }^{14)}$ signal transduction, ${ }^{15}$ ) and apoptosis. ${ }^{16)}$

Several lectins have been shown to have antitumor activities. It was reported that lectins isolated from mistletoe induced apoptosis in tumor cells U937 cells via the caspase dependent way. ${ }^{17)}$ And it also proved that mistletoe lectin showed more powerful antitumor effect on mice by oral route. ${ }^{18)}$ Sophora flavescens lectin induced apoptosis of HeLa cells in a time and dose-dependent manner. ${ }^{19)}$

In $2007 \mathrm{Hou}^{20)}$ reported that the total extract of Musca domestica larvae showed its antimicrobial activity and in vitro anti-tumor activity. However, what is specific the antitumor products in Musca domestica larvae and what is the function of the products are still not clear. So the objective of this study was to investigate the anti-tumor activity of the lectin from Musca domestica larva and explore its potential apoptotic induction mechanism.

\section{MATERIALS AND METHODS}

Musca domestica Larva Lectin Musca domestica was purchased from Tianjin Sanitation and Epidemic Prevention Station (Tianjin, P. R. China). Musca domestica larva lectin (MLL) was purified as previously described. ${ }^{18)}$

Cell Culture Human liver cancer cells BEL-7402 and human normal liver cells L-02 were purchased from Tianjin Medical University (Tianjin, P. R. China). All cells were routinely cultured in RPMI-1640 medium containing 10\% fetal bovine serum, $100 \mathrm{U} / \mathrm{ml}$ streptomycin, $100 \mathrm{U} / \mathrm{ml}$ penicillin, and $2 \mathrm{~mm}$ L-glutamine in a humidified cell incubator with an atmosphere of $5 \% \mathrm{CO}_{2}$ at $37^{\circ} \mathrm{C}$.

3-(4,5-Dimethylthiazol-2-yl)-2,5-diphenyltetrazolium Bromide (MTT) Assay The growth inhibitory effect of human liver cancer cells BEL-7402 and human normal liver cells L-02 was measured by MTT assay. The cell suspension $\left(1 \times 10^{5} / \mathrm{ml}\right)$ was partitioned into the wells of 96 -well plates (Costar, U.S.A.) with $0.1 \mathrm{ml} /$ well and cultured. After $24 \mathrm{~h}$, different concentrations of MLL were injected to the wells $(0.1 \mathrm{ml} /$ well $)$. The control group was given the same volume of dilute solution without any drugs. After $24 \mathrm{~h}, 48 \mathrm{~h}$ and $72 \mathrm{~h}$ culture, $5 \mathrm{~mm}$ MTT solution $(50 \mu \mathrm{l} /$ well) was added to the wells. After another $4 \mathrm{~h}$ culture, the supernatant was discarded and dimethyl sulfoxide (DMSO) was added (100 $\mu \mathrm{l} /$ well). The absorbance $(A)$ was read at a wavelength of 
$570 \mathrm{~nm}$ and a reference wavelength of $690 \mathrm{~nm}$ on an enzyme immunoassay instrument.

Hoechst 33258 Staining Apoptotic nuclear morphology was assessed with Hoechst 33258 purchased from Sigma (St. Louis, MO, U.S.A.). After $0 \mathrm{~h}$ and $48 \mathrm{~h}$ cultured in the RPMI1640 medium, the cells were harvested, and then stained with Hoechst 33258 at $37^{\circ} \mathrm{C}$ for $20 \mathrm{~min}$. The cells were washed and suspended again respectively in phosphate buffered saline (PBS) for morphologic observation under a fluorescent microscope (Olympus, Tokyo, Japan).

Measurement of Intracellular ROS The level of intracellular ROS was quantified by fluorescence with $2^{\prime}, 7^{\prime}$ dichlorofluorescin dictate (DCF-DA), a nonfluorescent compound, is deacetylated in viable cells to $2^{\prime}, 7^{\prime}$-dichlorofluorescein (DCF) by ROS. Cells were collected and incubated with $100 \mu \mathrm{M}$ DCF-DA for $30 \mathrm{~min}$ at $37^{\circ} \mathrm{C}$. Then cells were washed with PBS and the relative levels of fluorescence were quantified in a spectrophotofluorimeter. The measured fluorescence values were expressed as a percentage of the fluorescence in control cells. Glutathione peroxidase (GSH-PX) was measured according to the kits.

Flow Cytometric Analysis of Mitochondrial Transmembrane Potential $\left(\Delta \psi_{\mathrm{m}}\right)$ Cells were treated with MLL for the indicated time and harvested by centrifugation at $1000 \mathrm{~g}$ for $5 \mathrm{~min}$. Then the cells were stained with $1 \mu \mathrm{g} / \mathrm{ml}$ rhodamine- 123 and incubated for $30 \mathrm{~min}$ at $37^{\circ} \mathrm{C}$. Mitochondrial membrane potential $\left(\Delta \psi_{\mathrm{m}}\right)$ was analyzed by flow cytometer (Olympus, Tokyo).

Flow Cytometric Analysis of Cell Cycle and Ratio of Apoptotic Cells The collected cells were fixed with $500 \mathrm{ml}$ PBS and $10 \mathrm{ml} 70 \%$ ethanol at $4{ }^{\circ} \mathrm{C}$ overnight; then after washing twice with PBS, the cells were incubated with $1 \mathrm{ml}$ propidium iodide (PI) staining solution (PI $50 \mathrm{mg} / \mathrm{l}$ and RNase A $1 \mathrm{~g} / \mathrm{l}$ ) for $30 \mathrm{~min}$ at $4{ }^{\circ} \mathrm{C}$ in the dark condition. Samples were analyzed by a flow cytometer (Becton Dickinson, U.S.A.).

Western Blotting In order to discuss the potential apoptotic induction mechanism, the expression of characteristic apoptosis protein was investigated by Western blotting. The BEL-7402 cells were treated with MLL for 0, 6, 12, 24 and $48 \mathrm{~h}$ or co-incubated with the inhibitors (NAC and $\mathrm{z}$-VADFMK) for $48 \mathrm{~h}$. Both adherent and floating cells were collected. Western blot analysis was carried out by the method as described previously. ${ }^{16)}$ Mitochondria were isolated according to the Mitochondria Isolation Kit (KEYGEN). P53, Bax, Bcl-2, cytochrome $c$ and caspase-3, -9, the caspase inhibitor (Z-VAD-FMK) and ROS inhibitor (NAC) were purchased from Sigma (St. Louis, MO, U.S.A.).

\section{RESULTS}

Lectin MLL was purified by affinity chromatography using glactose-Sepharose 4B. The electrophoretic patterns of MLL were examined by sodium dodecyl sulfate-polyacrylamide gel electrophoresis (SDS-PAGE) in the absence and presence of 2-mercaptoethanol, the peak with molecular weight of $59 \mathrm{kDa}$ was observed (Fig. 1).

MTT Assay In order to discuss the toxicity of MLL between the cancer cell and the normal cell, the effect of MLL on BEL-7402 and L-02 cells was investigated by MTT assay. As shown in Fig. 2, MLL inhibited the proliferation of BEL-

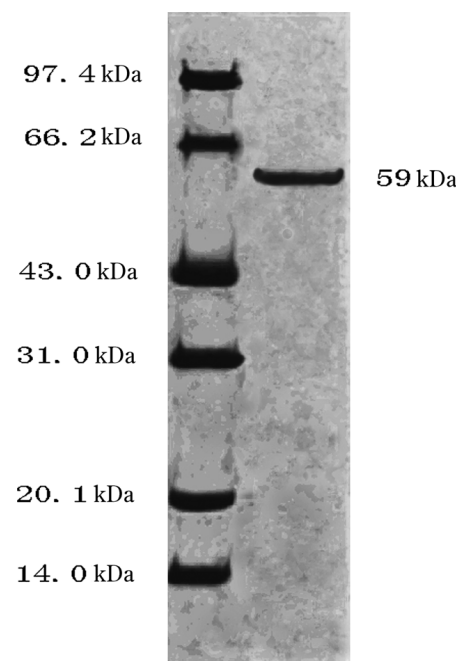

Fig. 1. The Purification Profile of MLL by SDS-PAGE (12\%)

Left lane: molecular mass standards. From top downward: $97.4 \mathrm{kDa}, 66.2 \mathrm{kDa}$, $43 \mathrm{kDa}, 31 \mathrm{kDa}, 20.1 \mathrm{kDa}$ and $14 \mathrm{kDa}$. Right lane: MLL (about $59 \mathrm{kDa}$ ).

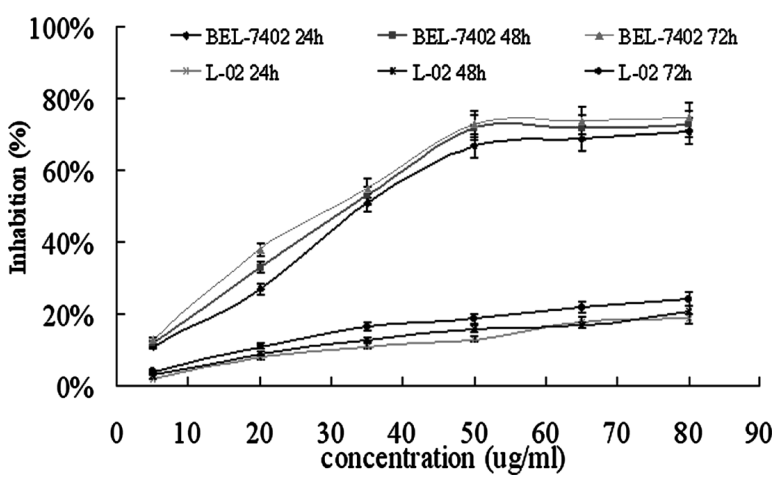

Fig. 2. Inhibition Effect of MLL in BEL-7402 and L-02 Cells

Cells were cultured in RPMI 1640 medium with MLL at the concentration of 5, 20, $35,50,65,80 \mu \mathrm{g} / \mathrm{ml}$ for 24,48 and $72 \mathrm{~h}$, respectively. The viability of cells was determined by the MTT assay. Results represent means \pm S.D.

7402 and L-02 cells in a dose and time dependent manner.

MLL possesses the abilities of remarkable inhibition especially on BEL 7402 cells $\left(\mathrm{IC}_{50}=35 \mu \mathrm{g} / \mathrm{ml}, 24 \mathrm{~h}\right.$ ), desirably, its toxicity to the normal liver cell L-02 cells is not obvious in the same dose and time, all these results suggested that MLL bears a greater susceptibility of the malignant cells.

Fluorescence Morphological Examination After cultured with MLL ( $35 \mu \mathrm{g} / \mathrm{ml})$ for $24 \mathrm{~h}$, morphologic changes of BEL7402 cells were confirmed by Hoechst 33258 staining. In control group, BEL-7402 nuclei were round and stained homogeneously with Hoechst 33258 (Fig. 3A), whereas the cells treated by MLL showed manifest fragmented DNA in nuclei (Fig. 3B). Marked apoptotic morphologic alterations including membrane and nuclear condensation also were observed by fluorescence microscopy. The results suggested that MLL could induce apoptosis of BEL-7402 cells.

Cell Cycle and Ratio of Apoptotic Cells The results of the cell cycle distribution are presented in Table 1. After BEL-7402 cells treated with $35 \mu \mathrm{g} / \mathrm{ml}$ of MLL at various time points, an arrest of cell cycle at G1 phase (from 25.2 to $48.6 \%$ ) and the significantly increased apoptotic rates (from 1.38 to $12.5 \%$ ) were observed (Table 1 ).

ROS and Mitochondrial Transmembrane Potential 
A

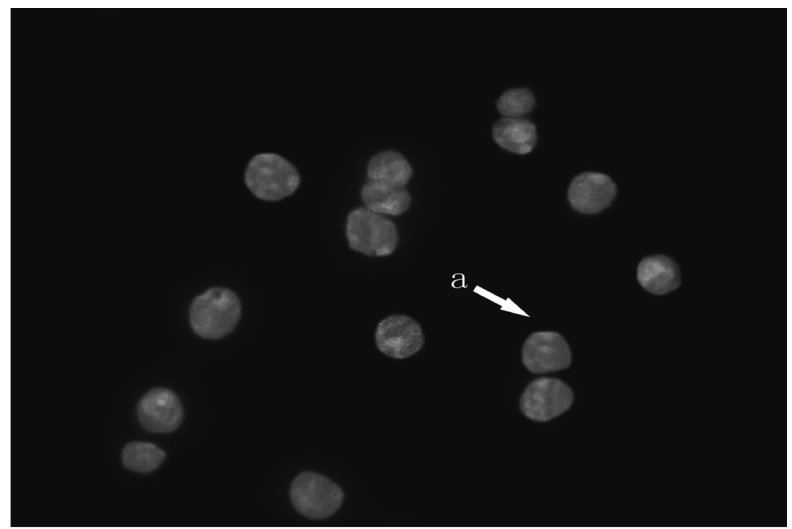

$\mathrm{B}$

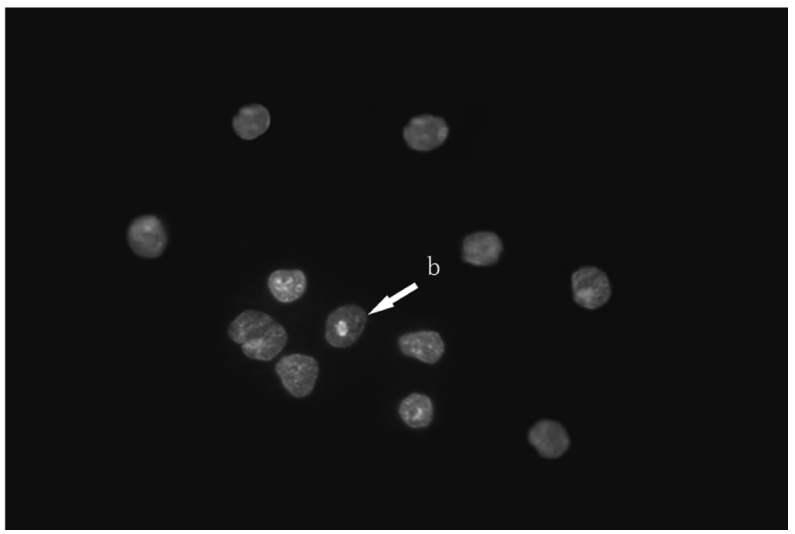

Fig. 3. MLL Inhibits Growth and Induces Apoptosis of BEL-7402 Cells by Fluorescence Morphological Examination

Induction of nuclear fragmentation in BEL-7402 cells $\left(2 \times 10^{5} \mathrm{cells} / \mathrm{ml}\right)$ were treated with MLL $(35 \mu \mathrm{g} / \mathrm{ml})$ for $0 \mathrm{~h}$ and $24 \mathrm{~h}$, then stained with Hoechst 33258. Cell morphology was observed under a fluorescence microscope $(\times 400)$. (a) Untreated normal cells: structure integrated, normal size, and uniformly blue. (b) Apoptotic cells, containing bright blue patches in the nuclei.

Table 1. Effect of MLL on Cell-Cycle Distribution of BEL-7402 Cells $(n=3)$

\begin{tabular}{|c|c|c|c|c|}
\hline $\begin{array}{l}\text { Time } \\
\text { (h) }\end{array}$ & $\begin{array}{c}\text { Apoptosis cell } \\
(\%)\end{array}$ & $\begin{array}{l}\text { G1 } \\
(\%)\end{array}$ & $\begin{array}{c}\mathrm{S} \\
(\%)\end{array}$ & $\begin{array}{c}\mathrm{G} 2 / \mathrm{M} \\
(\%)\end{array}$ \\
\hline 0 & $1.38 \pm 0.32$ & $25.2 \pm 0.45$ & $49.1 \pm 2.02$ & $25.6 \pm 0.94$ \\
\hline 24 & $5.07 \pm 1.55^{*}$ & $37.1 \pm 1.33 *$ & $43 \pm 1.96$ & $19.9 \pm 1.86^{*}$ \\
\hline 48 & $12.5 \pm 1.24 * *$ & $48.6 \pm 2.01 * *$ & $42.7 \pm 2.04 *$ & $8.69 \pm 1.84^{* *}$ \\
\hline
\end{tabular}

BEL-7402 cells were treated with MLL $(35 \mu \mathrm{g} / \mathrm{ml})$ for 0,24 and $48 \mathrm{~h}$, respectively. $* p<0.05$ and $* * p<0.01$ vs. $0 \mathrm{~h}$.

$\left(\Delta \boldsymbol{\psi}_{\mathrm{m}}\right)$ The increasing ROS production induced a variety of apoptotic signals and declined in cellular GSH content. GSH played a vital role in maintaining cellular ROS balance. In Fig. 4, the reduction of the activity of GPX enzyme and the increase in the content of ROS, suggested that MLL abrogated the GSH antioxidant system and led to ROS accumulated in large amount. Furthermore, after pretreated with ROS inhibitor $N$-acetyl-cysteine (NAC), the level of ROS was significantly inhibited. And the inhibition effort of MLL was blocked by NAC to BEL-7402 cells (Fig. 5). Treatment with NAC, which inhibited the production of intracellular ROS, significantly reversed the cell death induced by MLL treatment.

MLL treatment to BEL-7402 cells resulted in a rapid loss in $\Delta \psi_{\mathrm{m}}$ in a time-dependent manner (Fig. 6). Flow cytometric results revealed that high level of Rhodamine123 binding

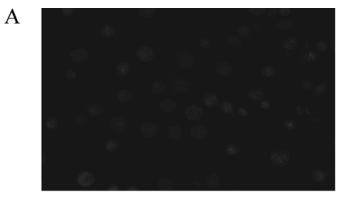

(A) $0 \mathrm{~h}$

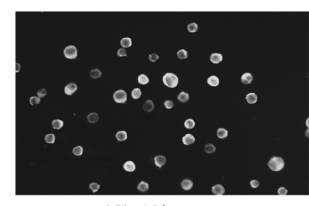

(C) $48 \mathrm{~h}$

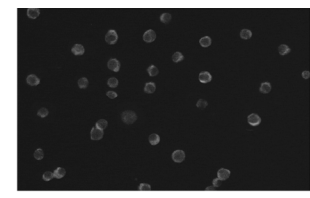

(B) $24 \mathrm{~h}$

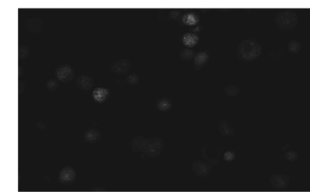

(D) MLL+NAC 48h
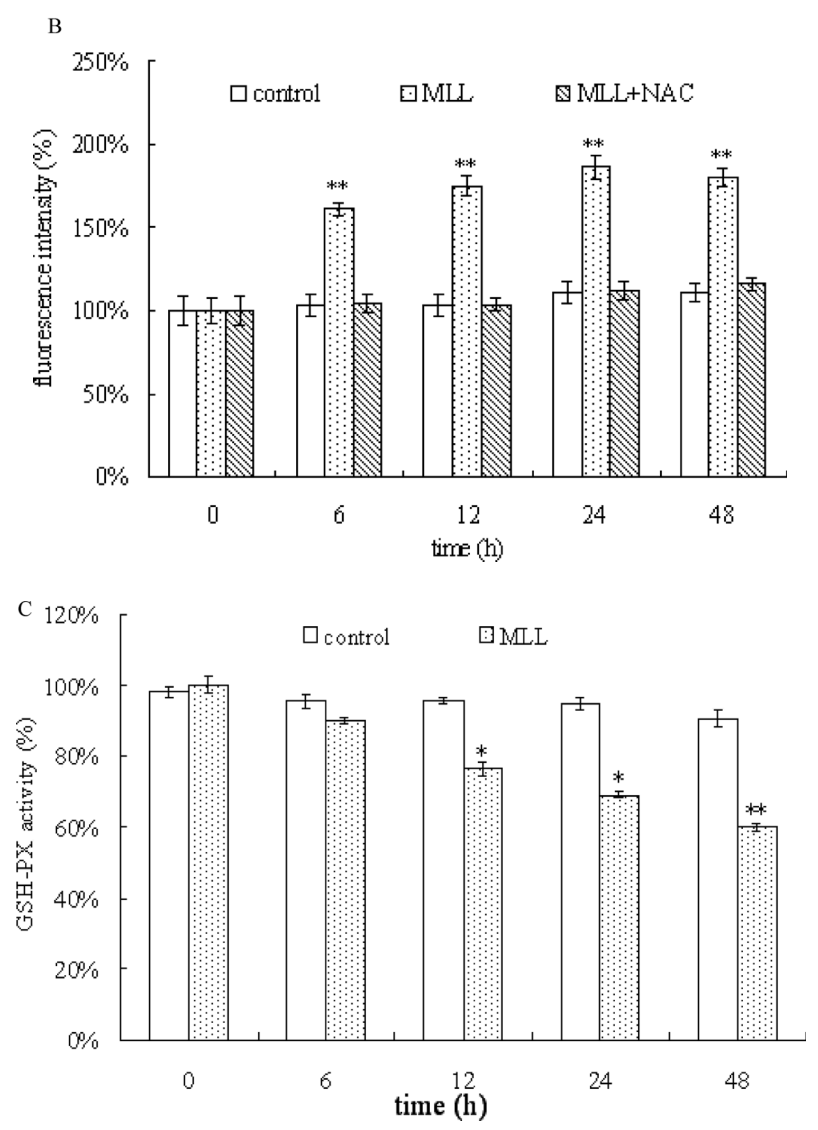

Fig. 4. ROS Content Change and GSH-PX Were Showed after Treated with MLL $(35 \mu \mathrm{g} / \mathrm{ml})$

(A) Cells were stained with DCF-DA. (B) Fluorescence intensity of ROS change after treated RPMI-1640 medium only (control), MLL and the mixture of NAC and MLL, respectively. (C) GSH-PX was decreased after treated with MLL. Results represent means \pm S.D. $* p<0.05$ and $* * p<0.01 v s$. control.

to the mitochondrial of untreated BEL-7402 cells. There is a decrease in the fluorescence after $12 \mathrm{~h}$ exposure to MLL. However, a significant decrease in the fluorescence (M2) was observed at $24 \mathrm{~h}(22.17 \%)$ after MLL treatment. Furthermore, loss in $\Delta \psi_{\mathrm{m}}$ was blocked by ROS inhibitor (NAC).

Western Blotting By Western blotting analysis, p53 started increasing from as early as $6 \mathrm{~h}$, reached a maximum level at $24 \mathrm{~h}$ and persisted up to $48 \mathrm{~h}$. At $48 \mathrm{~h}$, the level of p53 was found to decrease. The level of Bcl-2 was highly expressed in BEL-7402 cells and then decreased to low level after MLL treatment. On the other hand, the level of Bax increased significantly after $6 \mathrm{~h}$ and attained a peak at $24 \mathrm{~h}$ (Fig. 7). After treatment with MLL, the level of Bax protein was increased while the level of Bcl-2 was decreased, sug- 


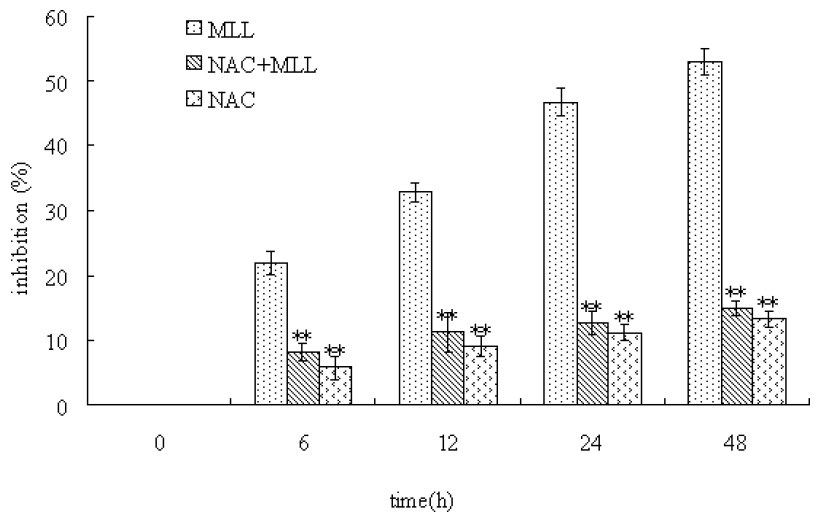

Fig. 5. Treatment with 5 mm NAC, Which Inhibited the Production of Intracellular ROS, Significantly Reversed the Cell Death Induced by MLL Treatment, as Determined by MTT Assay

$* * p<0.01 v s$. MLL.
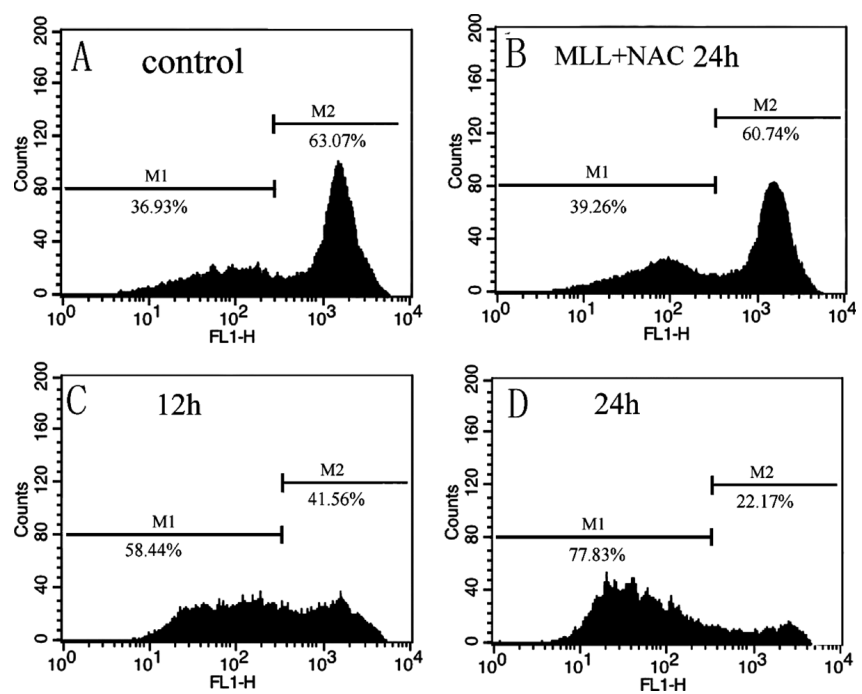

Fig. 6. Effect of MLL on the Changes in Mitochondrial Membrane Potential

Loss in mitochondrial membrane potential was analyzed by FCM with Rhodamine123 as fluorescent probe. After treated MLL, cells were stained with Rhodamine 123, analyzed on a flow cytometer. (A) Control $(0 \mathrm{~h})$. (B) Cells treated with MLL and NAC for $24 \mathrm{~h}$. (C) Cells treated with MLL for $12 \mathrm{~h}$. (D) Cells treated with MLL for $24 \mathrm{~h}$.

gesting that MLL induced apoptosis through up-regulation of Bax and down-regulation of Bcl-2 level.

Cytosolic cytochrome $c$ is a factor necessary for activation of apoptosis. It also showed that cyt $c$ was translocated from the mitochondrial membrane to the cytosol. The expression of cyt $c$ in cytosol was increased while that in mitochondria was decreased in the time depend way. In further research the process could be inhibited by NAC.

It has been demonstrated that induction of cell death is associated with initial activation of several procaspases, which lead to sequential activation of downstream caspase family protease. According to expression of caspase- 3 and caspase-9, BEL-7402 cells showed their activation of caspases after being treated with MLL. We observed a strong increase in caspases protein levels, and activation of the caspases was a time-dependent manner. To further define the role of caspase in MLL-induced apoptosis, cells were pretreated with caspase inhibitor Z-VAD-FMK $(100 \mu \mathrm{mol} / \mathrm{l}) 2 \mathrm{~h}$ before MLL. MLL-induced apoptosis was blocked by the
A

p53

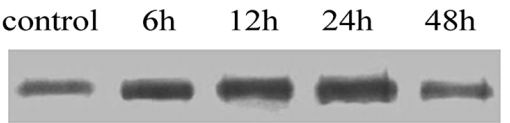

$53 \mathrm{kDa}$

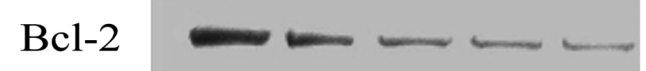

$26 \mathrm{kDa}$

\section{Bax}

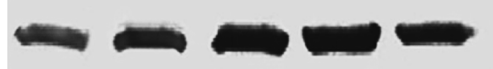

$23 \mathrm{kDa}$

$\beta$-actin

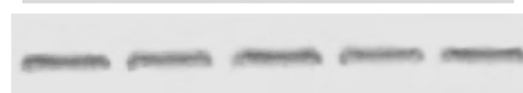

$46 \mathrm{kDa}$

\section{B}

\section{$\begin{array}{llllll}\text { control } & 6 & 12 & 24 & 48 & \text { MLL+NAC }\end{array}$}

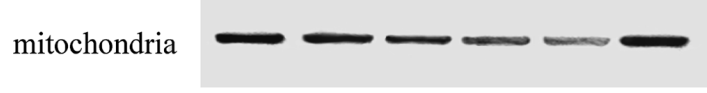

$12 \mathrm{kDa}$

cytosol

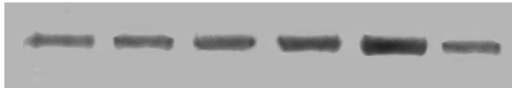

$12 \mathrm{kDa}$

$\beta$-actin

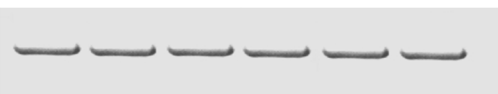

$46 \mathrm{kDa}$

C

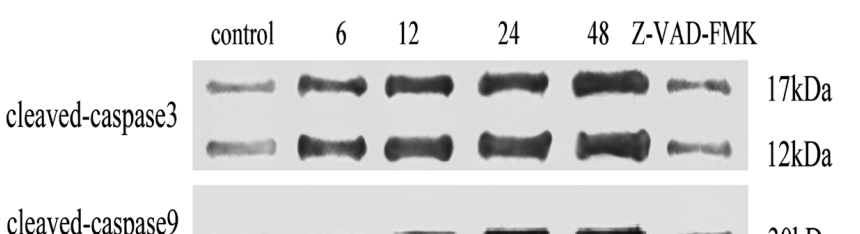

cleaved-caspase9

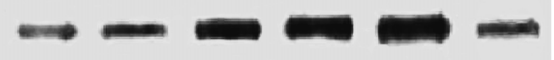

$30 \mathrm{kDa}$

$\beta$-actin

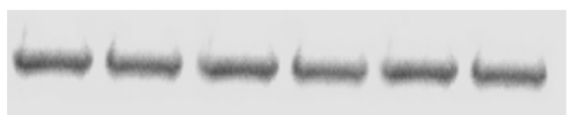

$46 \mathrm{kDa}$

Fig. 7. Cells Were Treated with MLL ( $35 \mu \mathrm{g} / \mathrm{ml})$ for $0,6,12,24$ and $48 \mathrm{~h}$, Respectively

Harvested cell lysates were subjected to Western blotting analysis with the indicated antibodies: Bcl-2, Bax, p53, caspase-9, caspase-3 and cyt $c$ antibodies was used to examine protein expression. (A) p53, Bax and Bcl-2 expression; (B) cyt $c$ released; (C) caspase activated.

broad caspase inhibitor Z-VAD-FMK.

\section{DISCUSSION}

MTT showed that MLL inhibited BEL-7402 cells proliferation in a dose and time-dependent manner, even MLL showed little inhibition to normal human cells L-02 cells. In my view the carbohydrate polymer in lectin has identified function, the carbohydrate polymer itself maybe has identified activity on cells, especially the malignant liver cells. Many articles have reported that lectins from plant bearing a greater susceptibility of the malignant cells, such as the polygonatum cyrtonema lectin. ${ }^{21)}$ And research on what is the accurate structure and how the carbohydrate polymer identifies the different kind cells are being conducted. The 
apoptosis induced by MLL was also confirmed by the observed changes in nuclear morphology. Compared to control cells, MLL treated BEL-7402 cells revealed nuclear fragmentation. And the nucleus and cytoplasm fragment would form apoptotic bodies that could be engulfed by phagocytes.

Many antitumor agents and DNA-damaging agents induce apoptotic cell death by arresting the cell cycle at the G1, S, or G2/M phase. ${ }^{22)}$ Our data demonstrated that MLL induced cell apoptosis by arresting BEL-7402 cells at the G1 phase. Components of the DNA damage checkpoint were essential for surviving exposure to DNA damaging agents which led to cell cycle arrest, DNA repair, and apoptosis in eukaryotes. $\left.{ }^{23}\right)$ Tumor suppressor p53 protein mediated checkpoint control and the apoptotic program, was critical for maintaining genomic integrity and preventing tumorigenesis. ${ }^{24)}$ It has been reported that p53 may induce two sets of genes upon stress signals. One set mainly functions in cell growth control and the other set act on apoptosis, such as Bcl-2. ${ }^{25)}$ Our data demonstrated that in BEL-7402 cells possessing p53, MLLinduced cells arrest and apoptosis were accompanied by the up-regulation of p53 protein level in a dose-dependent manner. These results indicated that the activation of the p53 pathway may be involved in MLL-induced cell cycle arrest and apoptosis in BEL-7402 cells.

Oxidative stress, characterized by overwhelming ROS, resulted in membrane lipid peroxidation, nitration of proteins, and degradation of DNA, all of which are associated with the course of apoptosis. ${ }^{26)}$ Cells were normally able to defend themselves against ROS damage through the use of enzymes such as NAC, superoxide dismutases, lactoperoxidases, glutathione peroxidases and peroxiredoxins. In our research MLL did not show the antitumor activity to cells because they were pretreated with NAC. Loss in $\Delta \psi_{\mathrm{m}}$ is a common phenomenon in apoptosis. ${ }^{27)}$ Loss in $\Delta \psi_{\mathrm{m}}$ is the early change in the mitochondria-mediated apoptosis. And ROS induced loss in $\Delta \psi_{\mathrm{m}}$. Our dates indicated that $\Delta \psi_{\mathrm{m}}$ reduction also could be blocked by NAC. It's reported that some chemotherapeutic drugs induced apoptosis because of overwhelming ROS. ${ }^{28)}$ And ROS itself presented at high levels also could cause severe damage to DNA, proteins and lipids, which may lead to apoptosis. ${ }^{29)}$ Our studies indicated that treatment with MLL induced increasing in ROS and loss in $\Delta \psi_{\mathrm{m}}$ which promoted apoptosis through cytochrome $c$ release from mitochondria to the cytosol.

Bcl-2 family members played the vital role in the regulation of the mitochondrial apoptotic pathway. More than 20 members of this family have been identified including proteins that control apoptosis. ${ }^{30)}$ Our studies revealed that MLL induce Bcl-2 decreased during the Bax increased. During apoptosis, cytochrome $c$ is where it is required for activation of caspase-3. But overexpression of $\mathrm{Bcl}-2$ prevents the translocation of cytochrome $c$, thereby blocking the apoptotic process; overexpression of Bax induces the release of cytochrome $c$ and thus induces cell death. ${ }^{31)}$ Caspases were a family of cysteine proteases which were activated during the apoptotic processes. After treated with MLL, the expression of cleaved-caspases-9 and cleaved-caspases-3 was increased. That activation of caspases was blocked by Z-VAD-FMK indicated MLL induced cells apoptosis through a caspase- dependent pathway.

These results indicated that MLL induced apoptosis in BEL-7402 cells through a mitochondrial-mediated ROS pathway. Based on all evidences reported above, it is reasonable to speculate that the MLL may be explored as a potential anti-cancer candidate agent for its antitumor activity. However our work is not enough, we will do more studies on the apoptosis induced by MLL in mitochondrial pathway in the future.

Acknowledgements We gratefully acknowledge the financial support by the National High Technology Research and Development Program of China (863 Program, No. 2007AA10Z319), the Chinese National Natural Science Foundation (20676103) and Tianjin Natural Science Foundation (07JCZDJC02900).

\section{REFERENCES}

1) Kinloch R. A., Treherne J. M., Furness L. M., Hajimohamadreza I., J. Trends Pharmacol. Sci., 20, 35-42 (1999).

2) Hengartner M. O., Nature (London), 407, 770_-776 (2000).

3) Meier P., Finch A., Evan G., Nature (London), 407, 796-801 (2000).

4) Hatano E., J. Gastroenterol. Hepatol., 1, $43-47$ (2007).

5) Pedersen P. L., J. Bioenerg. Biomembr., 39, 1-12 (2007).

6) Castino R., Bellio N., Nicotra G., Follo C., Trincheri N. F., Isidoro C., J. Free Radic. Biol. Med., 42, 1305-1316 (2007).

7) Adrain C., Martin S. J., J. Trends Biochem. Sci., 26, 390-397 (2001).

8) Cao X. H., J. Zool. Sci., 26, 249-253 (2009).

9) Tateno H., Ogawa T., Muramoto K., J. Biosci. Biotechnol. Biochem., 66, 604-612 (2002).

10) Pemberton R. T., J. Mycologicae Res., 98, 277-290 (1994).

11) Suvendu D., Biswajit S., Bidisha B., J. Comparative Biochemistry and Physiology Part C: Toxicology \& Pharmacology, 141, 76-84 (2005).

12) Zhao J. K., J. Toxicon, 53, 360-366 (2009).

13) Tasumi S., Ohira T., Kawazoe I., Suetake H., Suzuki Y., Aidak, J. Biol. Chem., 277, 27305-27311 (2002).

14) Inamori K., Saito T., Iwaki D., Nagira T., Iwanaga S., Arisaka F., Kawabata S., J. Biol. Chem., 274, 3272-3278 (1999).

15) Baptiste T. A., James A., Saria M., J. Exp. Cell. Res., 313, 652-664 (2007).

16) Kim W. H., Park W. B., Gao B., Jung M. H., Mol. Pharmacol., 66, 1383-1396 (2004).

17) Kim M. S., J. Gen. Pharmacol., 34, 349-355 (2000).

18) Ian F., Pryme. J. Cancer Detect. Prevent., 28, 52-56 (2004).

19) Zhen L., J. Phytomedicine, 15, 867-875 (2008).

20) Lixia H., J. Ethnopharmacol., 111, 227-231 (2007).

21) Bo L., Cancer Lett., 275, 54-60 (2009).

22) Kessel D., Luo Y. J., Cancer Lett., 151, 25-29 (2000).

23) Jaklevic B. R., Su T. T., J. Curr. Biol., 6, 23-32 (2004).

24) Hsin-Ling H., Chik O. C., Ravi K., Hung-Ju S., Jeffrey R. S., Chung Li S., Kang-Lin C., Yi-Rong C., Hsin-Fen H., Ronald B. G., J. DNA Repair, 6, 1319-1332 (2007).

25) Agarwal M. L., Taylor W. R., Chernov M. V., Chernova O. B., Stark G. R., J. Biol. Chem., 273, 1-4 (1998).

26) Fiskum G., J. Neurosurg Anesthesiol, 16, 108-110 (2004).

27) Marchetti P., Castedo M., Susin S. A., Zamzami N., Hirsch T., Macho A., Haeffner A., Hirsch F., Geuskens M., Kroemer G., J. Exp. Med., 3, 1155-1160 (1996).

28) Simizu S., Takada M., Umezawa K., Haeffner A., Hirsch F., Geuskens M., Kroemer G., J. Biol. Chem., 273, 26900-26907 (1998).

29) Simon H. U., Haj-Yehia A., Levi-Schaffer F., Imoto M., Apoptosis, 5, 415-418 (2000).

30) Burlacu A., J. Cell. Mol. Med., 7, 249-257 (2003).

31) Groc L., Bezind L., Jiang H., Jackson T. S., Levine R. A., J. Neurosci. Lett., 306, 198-202 (2001). 